\title{
Anxiety and depression among pharmacy students before and during COVID-19 pandemic
}

\author{
Walid Al-Qerem ${ }^{1 *}$, Alaa Hammad', Haneen A Amawi², Anan S Jarab³, Jonathan \\ Ling $^{4}$ \\ ${ }^{1}$ Department of Pharmacy, Al-Zaytoonah University of Jordan, Amman, ${ }^{2}$ Department of Pharmacy Practice, Yarmouk \\ University, Irbid, ${ }^{3}$ Department of Clinical Pharmacy, Faculty of Pharmacy, Jordan University of Science and Technology, Irbid, \\ Jordan, ${ }^{4}$ School of Health Sciences \& Wellbeing, University of Sunderland, Edinburgh Building, Chester Rd, Sunderland SR1 \\ 3SD, United Kingdom
}

*For correspondence: Email: waleed.qirim@zuj.edu.jo; Tel: +962775001232

Sent for review: 31 December 2020

Revised accepted: 22 April 2021

\begin{abstract}
Purpose: To evaluate factors associated with anxiety and depression among pharmacy students before and during COVID-19 pandemic.

Methods: The Beck Depression Inventory-II (BDI-II) and the State-Trait Anxiety Inventory (STAI) questionnaires were translated into Arabic and placed on the e-learning platforms of two Jordanian universities after conducting cognitive interviews. Validity and reliability of the two translated questionnaires were evaluated by conducting Exploratory Factor Analysis (EFA) and calculating Cronbach's alpha. T-tests and binary regression were conducted to evaluate factors associated with anxiety and depression among pharmacy students.

Results: Several factors were associated with depression and anxiety including being an international student $(p<0.05)$, living alone and away from their primary country of residence $(p<0.05)$, female gender $(p<0.01)$, and being a fifth-year student $(p<0.01)$.

Conclusion: $A$ tool to evaluate anxiety and depression among pharmacy students in Jordan has been successfully validated. Also, the results show that pharmacy students suffered from high levels of anxiety and depression, particularly during the COVID-19 pandemic.
\end{abstract}

Keywords: Anxiety, Depression, Pharmacy students, COVID-19

\begin{abstract}
This is an Open Access article that uses a fund-ing model which does not charge readers or their institutions for access and distributed under the terms of the Creative Commons Attribution License (http://creativecommons.org/licenses/by/4.0) and the Budapest Open Access Initiative (http://www.budapestopenaccessinitiative.org/read), which permit unrestricted use, distribution, and reproduction in any medium, provided the original work is properly credited.

Tropical Journal of Pharmaceutical Research is indexed by Science Citation Index (SciSearch), Scopus, International Pharmaceutical Abstract, Chemical Abstracts, Embase, Index Copernicus, EBSCO, African Index Medicus, JournalSeek, Journal Citation Reports/Science Edition, Directory of Open Access Journals (DOAJ), African Journal Online, Bioline International, Open-J-Gate and Pharmacy Abstracts
\end{abstract}

\section{INTRODUCTION}

Students enrolled in higher education programs often experience enormous anxiety and stress from their programs [1]. Stress is the degree to which people feel overpowered or incapable of handling a situation as a result of uncontrollable burdens [2]. While stress is a reaction to a perceived stress, anxiety is a response to stress. Long-lasting stress weakens the body, causes mental disorders like anxiety and depression, and reduces students' overall wellbeing [3]. Previous work found that stress can lead to sleep problems, constant assessment-related pressure, academic difficulties, poor physical health, and problems with peer friendships. In the 
United Kingdom and the United States of America, there is a strong perception that university students have increased need for psychological services, and that university counseling services frequently deal with severe mental illness.

Despite the importance of enhanced understanding of the effect of depression on students, a review of depression amongst U.S. college students and treatment outcomes from 1990 to 2009 reported only four studies and concluded that research on U.S. college student's depression and treatment outcomes was incomplete and inconclusive [4]. Hunt and Eisenberg also reported significant variations in criteria and methods for the inclusion and exclusion of depression diagnosis and determination of severity of depression. A further systematic review of published studies between January 1980 and May 2005 on the occurrence of anxiety and depression among medical students in Canada and United States showed high prevalence of depression, when compared to the general population [5]. The review also highlighted a paucity of research on factors responsible for depression among students, and the influence of these factors on academic performance, dropout rates and professional development.

The world was first exposed to a new strain of Corona virus a few months ago [6]. This strain, now known as COVID-19, is responsible for a pneumonic disease that first appeared in Wuhan, China, and then spread world-wide. The high virulence of COVID-19 forced governments to impose social distancing and lockdowns. This had a devastating effect on different sectors, particularly educational activities [7]. The continuation of student education during lockdown across the world may have a significant effect on the mental health of college students [6]. For example, it has been reported that depression and anxiety significantly increased among college students during the pandemic [8]. However, no previous work has focused on the effect of COVID-19 on the prevalence of stress and anxiety among students undertaking health-related programs.

Several tools are used to evaluate the level of anxiety and depression in different settings. The most commonly used are The Beck Depression Inventory (BDI)[9], the Center for Epidemiological Studies Depression Scale (CES-D)[10], and the State-Trait Anxiety Inventory (STAI) [11]. However, for proper use of these tools, they must be validated for the intended cohorts of participants. None of the previously mentioned tools has been validated in pharmacy school settings in Jordan.

This is the first study to validate the STAI and BDI-Il tools in pharmacy school settings in Jordan. The study also investigated the extent of stress, anxiety and depression among pharmacy students in Jordan before and during COVID-19. We hypothesized that there would be high levels of stress, anxiety, and depression among students who were enrolled during COVID-19. We also investigated demographic correlates with stress, anxiety, and depression among pharmacy students.

\section{METHODS}

Beck Depression Inventory-II (BDI-II) [9] is a validated questionnaire that measures the severity of depression symptoms. It contains 21 (0 - 3 scale) questions that evaluate different depression-related symptoms such as cognitive, affective, somatic, and vegetative symptoms. The BDI-II questionnaire has been translated into numerous languages, and it is used in different countries and settings. The minimal possible score of BDI-II is 0 , while the maximum score is 63. Respondents who score 21 and above are considered to have clinical depression.

The State-Trait Anxiety Inventory (STAI) [11] is composed of 40 questions, and it measures trait and anxiety state. All questions are rated on a 4point scale, with higher scores indicating higher degrees of anxiety. The questionnaire is divided into two parts: Trait anxiety (T-Anxiety) which measures personality trait associated with anxiety, and State anxiety (S-Anxiety) which measures the degree of anxiety in a specific moment. Each of these measurements is based on 20 questions. The minimum possible score for each part is 20 , while the maximum score is 8 . For college students, studies have shown that a score above 40 in each part indicates the presence of anxiety [11].

The BDI-II and STAI questionnaires were translated into Arabic and back-translated into English by different translators. The two English versions were compared and found to be comparable. In addition to the two main questionnaires, a brief demographic questionnaire was developed by the authors. This included questions about each student's age, gender, nationality, residential situation (living alone, with family or friends), average high school grade, current GPA, academic year, and parents' primary country of residence. 
Cognitive interviews were conducted with 70 students to ensure that all the questions in the translated questionnaires were clear to respondents. Few changes were made to the questionnaires after evaluating this feedback. One change involved removing the question on Loss of Interest in Sex due to the fact that many students felt uncomfortable answering it, especially since majority of the students were unmarried young females from conservative backgrounds. Data obtained from the cognitive interviews were not included in the final data.

The modified translated questionnaire and demographic sheet were formulated in Moodle questionnaire activity in universities' official websites. The activity was placed in different courses taught in different academic years (excluding courses taught in the $1^{\text {st }}$ semester of the $1^{\text {st }}$ year) in Moodle platform in two universities i.e Al-Zaytoonah University (a private university) and Al-Yarmouk University (a public university), between July 2019 and June 2020 . To encourage students to participate and provide candid answers, responses were collected anonymously, and feedbacks detailing their levels of anxiety and depression were displayed immediately they completed the questionnaire. Ethical approval was obtained from the University of Al-Zaytoonah ethics committee (approval no. 08/18/2018-2019). All participants gave consent for their data to be used in the research.

\section{Statistical analysis}

All statistical analyses were carried out using SPSS version 24 software. Categorical variables were presented as frequencies and percentages, while continuous variables are presented as mean \pm standard deviation (SD). Significance was taken at $p<0.05$. Responses were divided into two groups according to the date of submission. The first group comprised questionnaires submitted after the middle of March when the Jordanian government imposed lockdown (During COVID-19 group). Lockdown meant that distance learning was implemented by universities due to COVID-19 pandemic. The second group (Before COVID-19 group) covered all questionnaire submissions prior to that date.

\section{Data analysis}

The Kaiser-Meyer-Olkin (KMO) and the Bartlett's Test of Sphericity were applied to confirm the eligibility of the data for conducting Exploratory factor analysis (EFA). An EFA with oblimin rotation was used to identify the most suitable model for the study data in both questionnaires.
Kaiser-Meyer-Olkin value (KMO) and Bartlett's Test of Sphericity were used to determine the most representative model of each questionnaire data. All items with low communalities (< 0.4 ) were excluded from the analysis.

The number of factors to be included in the model was determined based on the results of the parallel analysis and scree plots. All items with inadequate factor loading $(<0.4)$, or with significant loading $(>0.4)$ in multiple factors were omitted. Factor correlation matrix was generated for confirmation of discriminant validity. Cronbach's alpha and Cronbach's alpha of deleted items were examined to confirm internal consistency.

The required sample size was determined based on question/participant ratio of $1: 10$. Therefore, for the current study, the required sample size was 400 students. The scores on the items in each sub-scale of the two questionnaires were summed to obtain the scores on the sub-scales. The scores on T-Anxiety, S-Anxiety and BDI-II represented the sum of scores on their subscales.

The association between different variables and scores on the two questionnaire sub-scales was analyzed using $t$-test, Mann Whitney $U$ test and Pearson correlation. The participants were divided into high/low T-Anxiety, S-Anxiety and depression levels using the cut-off points of the questionnaires as recommended by their original authors. Three stepwise (forward: conditional) binary regression analyses were used to evaluate the association of different variables with S-Anxiety, T-Anxiety and depression levels.

\section{RESULTS}

The questionnaires were distributed online and completed by 1085 college students. Majority of the students were females $(72.6 \%)$, Jordanian $(60.7 \%)$ and living with their families $(67.7 \%)$ (Table 1).

The STAI and BDI-II questionnaires were used to evaluate the students' anxiety and depression before and during COVID-19. The STAI questionnaire comprised 40 questions. The KMO test result was 0.9 , and Bartlett's Test of Sphericity was $\mathrm{X} 2(45)=28808.03(p<0.01)$, indicating that the STAI data were suitable for factor analysis. Scree plots and parallel analysis indicated that a four-factor model was the most suitable representation of the study data. The four factors were "State anxiety absent", "State anxiety present", "Trait anxiety absent", and "Trait anxiety present". As shown in Table 2, 
factor loadings for all the 40 items were higher than 0.4 , and the item "I feel confident" in the "State anxiety absent" factor had the lowest loading (0.42), and the item "I'm satisfied about myself" had lowest communality (0.36). All four factors had high Cronbach's alpha values above 0.8 , indicating acceptable internal consistency. Deletion of any item would not improve the reliability of the factor.

The BDI-II questionnaire comprised 20 questions. The KMO test result was 0.935 , and Bartlett's Test of Sphericity was $\mathrm{X} 2$ (45) = $7605.25,(p<0.01)$, indicating that the study data were suitable for factor analysis. Scree plots and parallel analysis indicated that a two-factor model was the most suitable representation of the study data. The two factors were "General depression symptoms" and "Health-related depression symptoms". As shown in Table 2, factor loadings for all 20 items were higher than 0.5 , and the factor "Crying" in the "General depression symptoms" had the lowest loading (0.56), while the item "Sadness" had the lowest communality (0.37). Both factors had high Cronbach's alpha values (above 0.8), indicating acceptable internal consistency. In addition, deleting any item would not improve the reliability of the factor.

Table 3 shows that during COVID-19, students had higher anxiety and depression in all the factors. The cut-off points recommended by the author of the original questionnaire were used to divide the participants into different groups: depression present (26.7 \%), high S-Anxiety levels $(73.7 \%)$, and high T-Anxiety levels (69.1 $\%$ ), relative to depression absent, low S-Anxiety levels and low T-Anxiety levels. A stepwise binary logistic regression (Table 4 ) indicated that students who completed the questionnaire during COVID-19 had significantly higher odds of having anxiety and depression than students who handed in their questionnaire before the pandemic. Another factor that was positively associated with depression was living alone. In contrast, age and GPA were negatively associated with depression. Age, living with family and being a student in the first three years of college were negatively associated with $T$ anxiety. Family residing in Jordan, and male gender were negatively associated with SAnxiety. Pearson correlation results showed that there were significant associations among TAnxiety, S-Anxiety and depression $(p<0.01)$.

\section{DISCUSSION}

This study validated STAI and BDI-II tools in pharmacy school settings in Jordan, and evaluated the variables that increase the anxiety and depression among pharmacy students. These variables included living alone, being in the final two years of college, and low GPA.

The STAI and BDI-II tools were initially translated from the original English questionnaires. Although different Arabic versions are available, translation form the original English language was preferred because the other Arabic versions were translated in different countries into different Arabic dialects.

The results of the present study indicated that the most suitable model for this sample was a four-factor model that included all the original 40 items. The four factors are State anxiety present, State anxiety absent, Trait anxiety absent and trait anxiety present.

Table 1: Demographics of the study sample

\begin{tabular}{|c|c|c|}
\hline Variable & $\begin{array}{c}\text { Frequency } \\
\text { (valid percent) }\end{array}$ & Mean (SD) \\
\hline $\begin{array}{l}\text { Academic year } \\
\text { First year } \\
\text { Second year } \\
\text { Third year } \\
\text { Fourth year } \\
\text { Fifth year }\end{array}$ & $\begin{array}{l}197(18.6) \\
209(19.8) \\
224(21.2) \\
202(19.1) \\
226(21.4)\end{array}$ & \\
\hline $\begin{array}{l}\text { COVID-19 } \\
\text { Before COVID-19 } \\
\text { During COVID-19 }\end{array}$ & $\begin{array}{l}665(62.9) \\
393(73.1)\end{array}$ & \\
\hline $\begin{array}{l}\text { Gender } \\
\text { Male } \\
\text { Female }\end{array}$ & $\begin{array}{l}290(27.4) \\
768(72.6)\end{array}$ & \\
\hline $\begin{array}{l}\text { Primary country } \\
\text { of residence } \\
\text { Inside Jordan } \\
\text { Outside Jordan }\end{array}$ & $\begin{array}{l}739(69.8) \\
319(30.2)\end{array}$ & \\
\hline $\begin{array}{l}\text { Nationality } \\
\text { Jordanian } \\
\text { Non-Jordanian }\end{array}$ & $\begin{array}{l}642(60.7) \\
416(39.3)\end{array}$ & \\
\hline $\begin{array}{l}\text { University } \\
\text { Al-Zaytoonah } \\
\text { Al-Yarmouk }\end{array}$ & $\begin{array}{l}948(89.6) \\
110(10.4)\end{array}$ & \\
\hline Age & & $20.55(1.49)$ \\
\hline GPA & & $\begin{array}{r}77.72 \\
(10.63)\end{array}$ \\
\hline $\begin{array}{l}\text { High school } \\
\text { average }\end{array}$ & & $83.59(7.55)$ \\
\hline $\begin{array}{l}\text { Living status } \\
\text { With Family } \\
\text { With Friend } \\
\text { Alone }\end{array}$ & $\begin{array}{c}811(76.70) \\
111(10.5) \\
136(12.9)\end{array}$ & \\
\hline
\end{tabular}


Similar results were reported in a Malaysian study [12] which found that the four-factor model was more suitable than the original, more commonly used, two-factor model which comprises State anxiety and Trait anxiety [11]. However, unlike the Malaysian model [12] that is devoid of three items, the present study retained the original 40 items. The present study model was also different from the STAI Arabic version that was validated in a Saudi dental setting as a one-factor model composed of 40 items [13]. The validation results of the BDI-II tool suggests that the most suitable model for the study sample was a two-factor model with 20 items. The two factors were General expression symptoms composed of 15 items, and Health-related depression symptoms comprising 5 items. The final model included 20 items. The item "Loss of interest in sex" was omitted in the validity phase because of the conservative nature of the Jordanian society, and the characteristics of the target sample which contained many young unmarried women. The distribution of the items in the two factors in this study differs from that of items in the original Somatic-Affective and Cognitive factors [9]. Different models for BDI-II have been suggested in the literature. For example, studies conducted on a sample of adolescents from Hong Kong and the United states suggested that a hierarchical model was the best fit for the BDI-II tool [14]. Moreover, a three-factor model was suggested in a Bahraini study that used an Arabic version of BDI-II [15].
The COVID 19 outbreak is a global crisis. Many countries have been placed under lockdown since the outbreak of the pandemic. Similar to previous widespread infectious pandemics (SARS, Ebola, H1N1 and MERS), COVID 19 raises concerns related to the spreading of panic and anxiety among populations worldwide. This may result in significant adverse mental health outcomes in different sectors. Current research evidence suggests that COVID-19 quarantine resulted in an increased prevalence of stress, anxiety and depression among people worldwide. The higher levels of psychological problems could be due to factors such as length of lockdown and quarantine periods, lack of physical activity, boredom, loss of jobs, financial challenges, and fear of infection.

The COVID 19 pandemic led to a complete shutdown of most of the academic institutions worldwide, including all schools and universities in Jordan. As a result, the Jordanian Ministry of Higher Education suspended on-campus classes and resorted to online learning using different platforms. Up to the date of writing this manuscript, students are still using these online learning systems for their education. The new experience is associated with several challenges, including a significant level of uncertainty that may negatively affect the quality of education and the mental health of students. Studies before the COVID 19 pandemic showed that students in general are exposed to higher levels of stress and anxiety than other populations[16].

Table 2: Communalities, factor loadings, and reliability of STAI and BDI-II

\begin{tabular}{|c|c|c|c|c|c|c|}
\hline $\begin{array}{l}\text { Factor } \\
\text { Name }\end{array}$ & $\begin{array}{l}\text { Factor } \\
\text { Number }\end{array}$ & $\begin{array}{c}\text { Communal- } \\
\text { ities }\end{array}$ & $\begin{array}{c}\text { Factor } \\
\text { loadings }\end{array}$ & $\begin{array}{c}\text { Cronbach's } \\
\text { Alpha }\end{array}$ & $\begin{array}{l}\text { Cronbach's Alpha } \\
\text { if item deleted }\end{array}$ & Mean (SD) \\
\hline \multicolumn{7}{|l|}{ STAI } \\
\hline $\begin{array}{l}\text { State anxiety } \\
\text { Present }\end{array}$ & $\begin{array}{c}3,4,6,7,9 \\
12,13,14 \\
17,18\end{array}$ & $0.42-0.70$ & $0.57-0.86$ & 0.91 & $0.89-0.90$ & $24.48(7.81)$ \\
\hline $\begin{array}{l}\text { State anxiety } \\
\text { Absent }\end{array}$ & $\begin{array}{c}1,2,5,8,10,11,1 \\
5,16 \\
19,20\end{array}$ & $0.41-0.65$ & $0.42-0.77$ & 0.90 & $0.89-0.90$ & $25.03(7.28)$ \\
\hline $\begin{array}{l}\text { Trait anxiety } \\
\text { Absent }\end{array}$ & $\begin{array}{c}21,23,26,27,30 \\
33,34,36,39\end{array}$ & $0.36-0.62$ & $0.55-0.80$ & 0.89 & $0.87-0.89$ & $21.36(6.50)$ \\
\hline $\begin{array}{l}\text { Trait anxiety } \\
\text { Present }\end{array}$ & $\begin{array}{c}22,24,25,28,29 \\
31,32,35,37,38 \\
40\end{array}$ & $0.39-0.64$ & $0.48-0.82$ & 0.90 & $0.89-0.90$ & $24.79(7.82)$ \\
\hline \multicolumn{7}{|l|}{ BDI-II } \\
\hline $\begin{array}{l}\text { General } \\
\text { Depression } \\
\text { symptoms }\end{array}$ & $\begin{array}{c}1,2,3,4,5,6,7,8 \\
9,10 \\
11,12,13 \\
14,15\end{array}$ & $0.37-0.62$ & $0.56-0.80$ & 0.80 & $0.88-0.89$ & $10.24(8.11)$ \\
\hline $\begin{array}{l}\text { Health-related } \\
\text { depression } \\
\text { symptoms }\end{array}$ & $\begin{array}{c}16,17,18 \\
19,20\end{array}$ & $0.52-0.61$ & $0.70-0.82$ & 0.81 & $0.76-0.78$ & $3.31(3.28)$ \\
\hline
\end{tabular}


Table 3: Subgroups means (standard deviations) in STAI and BDI-II factor scores

\begin{tabular}{|c|c|c|c|c|c|c|c|c|c|c|c|c|}
\hline Variable & \multicolumn{2}{|l|}{$\begin{array}{l}\text { State anxiety } \\
\text { Present }\end{array}$} & \multicolumn{2}{|c|}{$\begin{array}{l}\text { State anxiety } \\
\text { Absent }\end{array}$} & \multicolumn{2}{|l|}{$\begin{array}{l}\text { Trait anxiety } \\
\text { Absent }\end{array}$} & \multicolumn{2}{|l|}{$\begin{array}{l}\text { Trait anxiety } \\
\text { Present }\end{array}$} & \multicolumn{2}{|c|}{$\begin{array}{l}\text { Health related } \\
\text { depression } \\
\text { symptoms }\end{array}$} & $\begin{array}{l}\text { General } \\
\text { Depression } \\
\text { symptoms } \\
\text { Mean }\end{array}$ & $\begin{array}{l}P \text { - } \\
\text { value }\end{array}$ \\
\hline COVID-19 & & & & & & & & & & & & \\
\hline $\begin{array}{l}\text { Before } \\
\text { During }\end{array}$ & $\begin{array}{l}23.49(7.71) \\
26.17(7.68)\end{array}$ & $<0.01$ & $\begin{array}{l}24.44(7.20) \\
26.01(7.31)\end{array}$ & $<0.01$ & $\begin{array}{l}20.31(6.23) \\
23.12(6.560\end{array}$ & $<0.01$ & $\begin{array}{l}22.81(7.21) \\
28.13(7.71)\end{array}$ & $<0.01$ & $\begin{array}{l}2.96(3.00) \\
3.89(3.62)\end{array}$ & $<0.01$ & $\begin{array}{l}8.70(6.77) \\
12.85(9.43)\end{array}$ & $<0.01$ \\
\hline Gender & & & & & & & & & & & & \\
\hline Male & 22.99(7.93) & $<0.01$ & $24.77(7.35)$ & $\mathrm{N} / \mathrm{S}$ & 20.86(6.85) & N/S & $24.71(8.20)$ & $\mathrm{N} / \mathrm{S}$ & $3.60(3.82)$ & $\mathrm{N} / \mathrm{S}$ & $9.85(8.46)$ & $\mathrm{N} / \mathrm{S}$ \\
\hline $\begin{array}{l}\text { Female } \\
\text { Academic }\end{array}$ & $25.05((7.69)$ & & $25.12(7.26)$ & & $21.55(6.35)$ & & $24.82(7.68)$ & & $3.20(3.04)$ & & $10.49(7.97)$ & \\
\hline year & $24.31(7.66)$ & & $24.91(7.46)$ & & $20.37(6.36)$ & & $24.23(7.85)$ & & $3.05(3.55)$ & & $9.62(7.92)$ & \\
\hline First year & $23.94(7.76)$ & & $25.34(6.80)$ & & $21.05(6.36)$ & & $25.00(7.23)$ & & $3.32(3.14)$ & & $10.79(8.17)$ & \\
\hline Second & $24.21(7.86)$ & N/S & $24.52(7.84)$ & N/S & $21.65(6.88)$ & 0.04 & $24.46(8.02)$ & $\mathrm{N} / \mathrm{S}$ & $3.28(3.35)$ & $\mathrm{N} / \mathrm{S}$ & $10.06(7.83)$ & $\mathrm{N} / \mathrm{S}$ \\
\hline year & $24.89(7.45)$ & & $25.39(6.92)$ & & 20.91(6.33) & & 25.44(7.61) & & $3.56(3.33)$ & & 10.95(7.79) & \\
\hline $\begin{array}{l}\text { Third year } \\
\text { Fourth } \\
\text { year }\end{array}$ & $25.03(8.25)$ & & $25.02(7.32)$ & & $22.63(6.33)$ & & 24.81(8.34) & & $3.31(3.22)$ & & $9.81(8.75)$ & \\
\hline Fifth year & & & & & & & & & & & & \\
\hline $\begin{array}{l}\text { Primary } \\
\text { country of } \\
\text { residence }\end{array}$ & & & & & & & & & & & & $\mathrm{N} / \mathrm{S}$ \\
\hline Inside & $24.27(7.89)$ & N/S & $24.69(7.30)$ & 0.02 & $21.17(6.85)$ & $N / S$ & $24.37(7.73)$ & $<0.01$ & $3.20(3.17)$ & $\mathrm{N} / \mathrm{S}$ & 9.99(8.24) & \\
\hline $\begin{array}{l}\text { Jordan } \\
\text { Outside } \\
\text { Jordan } \\
\text { Nationality }\end{array}$ & $24.97(7.59)$ & & $25.80(7.20)$ & & $21.79(6.30)$ & & $25.75(7.96)$ & & $3.54(3.51)$ & & 10.81(7.79) & \\
\hline Jordanian & $20.44(7.82)$ & 0.01 & $24.45(7.22)$ & $<0.01$ & $21.19(6.68)$ & & $24.16(7.78)$ & $<0.01$ & $3.23(3.21)$ & & $9.71(7.78)$ & $<0.01$ \\
\hline $\begin{array}{l}\text { Non- } \\
\text { Jordanian } \\
\text { Living }\end{array}$ & $25.22(7.74)$ & & $25.90(7.30)$ & & $21.65(6.21)$ & $\mathrm{N} / \mathrm{S}$ & $25.75(7.81)$ & & $3.42(3.38)$ & $\mathrm{N} / \mathrm{S}$ & 11.06(8.55) & \\
\hline Condition & $24.31(8.00)$ & & $24.80(7.37)$ & & 21.12(7.37) & & $24.40(7.81)$ & & $3.22(3.23)$ & & $9.85(8.04)$ & \\
\hline Family & $24.68(6.49)$ & N/S & $25.69(6.33)$ & $\mathrm{N} / \mathrm{S}$ & $21.75(5.68)$ & N/S & $26.05(7.43)$ & 0.01 & $3.00(2.74)$ & $<0.01$ & $11.31(7.73)$ & 0.01 \\
\hline $\begin{array}{l}\text { Friend } \\
\text { Alone }\end{array}$ & $25.35(7.780$ & & $25.81(7.45)$ & & $22.43(6.39)$ & & 26.04(8.10) & & $4.10(3.82)$ & & $11.72(8.62)$ & \\
\hline
\end{tabular}


Table 4: Binary regression results

\begin{tabular}{|c|c|c|c|c|c|c|c|c|c|}
\hline \multirow[t]{3}{*}{ Variable } & \multicolumn{3}{|c|}{ T-Anxiety } & \multicolumn{3}{|c|}{ S-Anxiety } & \multicolumn{3}{|c|}{ Depression } \\
\hline & \multirow{2}{*}{$\begin{array}{l}\text { Odds } \\
\text { ratio }\end{array}$} & \multicolumn{2}{|c|}{$95 \% \mathrm{Cl}$} & \multirow{2}{*}{$\begin{array}{l}\text { Odds } \\
\text { ratio }\end{array}$} & \multicolumn{2}{|c|}{$95 \% \mathrm{Cl}$} & \multirow{2}{*}{$\begin{array}{l}\text { Odds } \\
\text { ratio }\end{array}$} & \multicolumn{2}{|c|}{$95 \% \mathrm{Cl}$} \\
\hline & & Lower & Upper & & Lower & Upper & & Lower & Upper \\
\hline Gender (Male) & & $\mathrm{N} / \mathrm{S}$ & & $0.64^{* *}$ & 0.47 & 0.88 & & $\mathrm{~N} / \mathrm{S}$ & \\
\hline During COVID-19 & $3.08^{* *}$ & 2.26 & 4.21 & $1.88^{\star *}$ & 1.37 & 2.57 & $1.98^{\star *}$ & 1.48 & 2.64 \\
\hline Age (Years) & $0.95^{\star}$ & 0.922 & 0.99 & & $\mathrm{~N} / \mathrm{S}$ & & $0.94^{* *}$ & 0.90 & 0.97 \\
\hline GPA & & $\mathrm{N} / \mathrm{S}$ & & & $\mathrm{N} / \mathrm{S}$ & & $0.98^{* *}$ & 0.96 & 0.99 \\
\hline Living alone & & $\mathrm{N} / \mathrm{S}$ & & & $\mathrm{N} / \mathrm{S}$ & & $1.61^{*}$ & 1.08 & 2.41 \\
\hline $\begin{array}{l}\text { Permanent family } \\
\text { residency inside Jordan }\end{array}$ & & $\mathrm{N} / \mathrm{S}$ & & $0.70^{*}$ & 0.51 & 0.97 & & $\mathrm{~N} / \mathrm{S}$ & \\
\hline Living with family & $0.69^{*}$ & 0.49 & 0.97 & & $\mathrm{~N} / \mathrm{S}$ & & & $\mathrm{N} / \mathrm{S}$ & \\
\hline \multicolumn{10}{|l|}{ Academic Year } \\
\hline First Year & $0.44^{* *}$ & 0.29 & 0.69 & & $\mathrm{~N} / \mathrm{S}$ & & & $\mathrm{N} / \mathrm{S}$ & \\
\hline Second Year & $0.52^{* *}$ & 0.33 & 0.80 & & N/S & & & N/S & \\
\hline Third Year & $0.54^{* *}$ & 0.36 & 0.84 & & $\mathrm{~N} / \mathrm{S}$ & & & $\mathrm{N} / \mathrm{S}$ & \\
\hline $\begin{array}{l}\text { Fourth Year } \\
\text { Reference (Fifth Year) }\end{array}$ & 0.86 & 0.55 & 1.36 & & $\mathrm{~N} / \mathrm{S}$ & & & $\mathrm{N} / \mathrm{S}$ & \\
\hline
\end{tabular}

Note: N/S: not significant; ${ }^{*} p<0.05,{ }^{* *} p<0.01$

Moreover, it has been reported that anxiety and depression increase during pandemics. However, there are limited publications related to COVID-19 with respect to the mental health of university students. A study by Wang et al evaluated anxiety and depression as well as the associated factors during the initial stages of COVID-19 outbreak among the general population in China. The results showed that being a student was associated with increased anxiety and depression [17]. Another study conducted to evaluate the impact of COVID-19 on Chinese university students revealed that students showed significantly higher anxiety than the general population during the COVID-19 outbreak [18]. Moreover, students in medical fields of study had higher anxiety levels than other university students.

The present study reported several mental health aspects in pharmacy students in two universities in Jordan. The results of this study which are consistent with previous reports, indicate that pharmacy students showed higher levels of depression and anxiety during the shutdown of schools and the transition to online education due to COVID-19. The high levels of depression may be attributed to a variety of factors, including sudden deprivation of university campus interactions among students. The absence of the usual physical interaction with friends, colleagues and teaching staff can result in reduced motivation, and may negatively affect the learning process. In addition, students faced several technical issues in online learning, including unstable home internet connections and the sudden failure of online education systems. Moreover, undergraduate students are usually younger than the general adult population, with ages within the range of $18-24$ years. People in this age range are usually more vulnerable to influences of news and overexaggeration of fears from the social media [19]. Another important factor is that some teaching staff and students lack training and preparation relevant to the use of online teaching and learning. Teaching staff and educators should consider these factors while delivering online learning.

A previous study by Rajiah and Saravanan evaluated the role of psychological interventions in reducing test anxiety among first year pharmacy students. An earlier study demonstrated the effectiveness of psychoeducation, relaxation therapy, and systematic desensitization in students with moderate-to-high level of test-anxiety [20]. Accordingly, online- and smartphone-based psychological interventions should be provided for students so as to reduce the negative impacts associated with online education during the COVID-19 pandemic. The online psychological interventions should include cognitive behavioral therapy, counseling services and support networks. A proper psychoeducation about the causes, symptoms, and consequences of online education-related depression and anxiety should be provided. Special attention should be focused on female students, non-Jordanian students, students living alone, as well as students in their last years before graduation. In the present study, these vulnerable groups showed higher levels of depression or anxiety, or both, when compared to other students.

Previous reports showed that female students in general were more likely to express higher anxiety and depression symptoms than male students [21]. It has been reported that female 
students have higher emotional and psychological responses to stressors [22]. A study by Fawzy and Hamed showed that female medical students in Egyptian university had higher levels of anxiety and depression than male students [23]. The anxiety was also higher among female students than among male students during COVID-19 quarantine [18]. Indeed, our study also showed that female pharmacy students had significantly higher anxiety than their male counterparts in State anxiety present. This suggests that female students in health-related fields tend to be more competitive and more concerned about examinations and achieving higher marks than the male students. Moreover, female students are likely to spend more time studying, with fewer physical activities than male students.

International students and those who study abroad suffer from additional stressors and challenges than indigenous students. Studying in another country can be an interesting and joyful experience, but it might also be stressful. Encountering different cultures and environments may lead to emotional instability. This may be compounded by other stressors such as home sickness, limited relationships with other students and teaching staff, limited budgets, and language barriers. Previous studies revealed that international students deal with acculturationrelated stress when they leave their families, friends and communities to start adapting to new cultures in a foreign country, especially at the early stages of their studies [24]. Another study which evaluated the predictors of depression and anxiety among international students indicated the value of social support in reducing overseas student's anxiety and depression [22]. In the present study, non-Jordanians had higher anxiety and depression in most of the factors, when compared with Jordanian students. Students living alone had higher scores in Tanxiety and depression factors. Students whose permanent country of residence was outside Jordan had higher anxiety in State anxiety absent and Trait anxiety present. Accordingly, more support and counseling are needed for this particular group of students.

This study showed that fifth-year college students experienced higher anxiety levels than the other students in Trait anxiety absent, this could be due to a variety of causes. The students at this stage are close to graduation and are likely to be concerned about their future careers. There are over 15 private and public universities that award a degree in pharmacy in Jordan. This results in exceedingly high number of pharmacy degree holders each year, alongside a limited number of job vacancies in the pharmacy sector, thereby placing the students under additional stress and anxiety.

\section{Limitations of the study}

This study has several limitations. In the first place, the results were collected from selfadministered questionnaires. Thus, the data relied upon might be subjective. Secondly, the study was conducted in only two universities in Jordan. This may limit the generalizability of the results. Thus, a larger study involving different regions and universities in Jordan is needed. Thirdly, no comparison was made with the general population or non-pharmacy students, and the baseline mental health of the students prior to attending pharmacy schools was not determined. Fourthly, this study is not interventional and psycho-education and counseling services were not provided. In view of these limitations, further studies are needed to confirm the utility of the findings of this study for pharmacy students.

\section{CONCLUSION}

This study validates the BDI-II and STAI tools in pharmacy school settings in Jordan. The study shows that pharmacy students had higher levels of anxiety and depression during the COVID 19 quarantine period, and during the use of online education systems. Effective preventive measures should be established to help students in general, and during the COVID 19 pandemic, in particular. These tools should be based on a deeper understanding of the barriers and facilitators faced by students using online learning platforms. For example, online psychological interventions and supportive counseling webinars should be developed and provided to students to deal with such challenges. Students should be able to receive help whenever it is needed.

\section{DECLARATIONS}

\section{Conflict of interest}

No conflict of interest is associated with this work.

\section{Contribution of authors}

We declare that this work was done by the author(s) named in this article and all liabilities pertaining to claims relating to the content of this article will be borne by the authors. This study was conceived and designed by Walid Al-Qerem 
and Alaa Hammad. The data were collected by Walid Al-Qerem, Alaa Hammad, and Anan Jarab. The data analysis was done by Walid Al-Qerem. The article was written by Walid Al-Qerem, Alaa Hammad, Anan Jarab, and Jonathan Ling.

\section{Open Access}

This is an Open Access article that uses a funding model which does not charge readers or their institutions for access and distributed under the terms of the Creative Commons Attribution License (http://creativecommons.org/licenses/by/ 4.0) and the Budapest Open Access Initiative (http://www.budapestopenaccessinitiative.org/rea d), which permit unrestricted use, distribution, and reproduction in any medium, provided the original work is properly credited.

\section{REFERENCES}

1. Foureur M, Besley K, Burton G, Yu N, Crisp J. Enhancing the resilience of nurses and midwives: Pilot of a mindfulness-based program for increased health, sense of coherence and decreased depression, anxiety and stress. Contemp Nurse. 2013; 45(1): 114-125. doi:10.5172/conu.2013.45.1.114

2. Turner C. How Do They Do It? A Phenomenological Description of Stress and Coping in Radiation Therapists. Dr Diss Proj. December 2016.

3. Lovallo WR, Buchana TW. Stress Hormones in Psychophysiological Research: Emotional, Behavioral, and Cognitive Implications. 4th ed. (Cacioppo J, Tassinary L, Berntson G, eds.). Cambridge University Press; 2017.

4. Hunt J, Eisenberg D. Mental Health Problems and HelpSeeking Behavior Among College Students. J Adolesc Heal. 2010; 46(1) :-10. doi:10.1016/j.jadohealth.2009.08.008

5. Chrousos GP. Stress and disorders of the stress system. Nat Rev Endocrinol. 2009; 5(7) :374-381. doi:10.1038/nrendo.2009.106

6. Cao W, Fang Z, Hou G, et al. The psychological impact of the COVID-19 epidemic on college students in China. Psychiatry Res. 2020; $287 \quad$ :112934. doi:10.1016/j.psychres.2020.112934

7. Billy M. The Influence of Dynamic Organizations and the Application of Digital Innovations to Educational Institutions in the World during the COVID-19 Pandemic. SSRN Electron J. April 2020. doi:10.2139/ssrn.3588233

8. Liu X, Liu J, Zhong X. Psychological State of College Students During COVID-19 Epidemic. SSRN Electron J. 2020. doi:10.2139/ssrn.3552814

9. Beck AT, Steer RA, Ball R, Ranieri WF. Comparison of Beck depression inventories -IA and -II in psychiatric outpatients. J Pers Assess. 1996; 67(3) :588-597. doi:10.1207/s15327752jpa6703_13

10. Radloff LS. The CES-D Scale. Appl Psychol Meas. 1977; 1(3) :385-401. doi:10.1177/014662167700100306

11. Spielberger $C D$. State-Trait Anxiety Inventory: $A$ Comprehensive Bibliography. MIND GARDEN; 1989.

12. Bee Seok C, Abd Hamid H, Mutang J, Ismail R. Psychometric Properties of the State-Trait Anxiety Inventory (Form Y) among Malaysian University Students. Sustainability. 2018; 10 :3311. doi:10.3390/su10093311

13. Bahammam MA. Validity and reliability of an Arabic version of the state-trait anxiety inventory in a Saudi dental setting. Saudi Med J. 2016; 37(6): 668-674. doi:10.15537/smj.2016.6.13935

14. Byrne BM, Stewart SM, Kennard BD, Lee PWH. The Beck Depression Inventory-II: Testing for Measurement Equivalence and Factor Mean Differences Across Hong Kong and American Adolescents. Int J Test. 2007; 7(3) :293-309. doi:10.1080/15305050701438058

15. Al-Musawi NM. Psychometric properties of the Beck Depression Inventory-II with University students in Bahrain. J Pers Assess. 2001; 77(3) :568-579. doi:10.1207/S15327752JPA7703_13

16. American College Health Association. American College Health Association-National College Health Assessment II: Reference Group Executive Summary Spring 2015.; 2015.

17. Wang C, Pan R, Wan X, et al. Immediate psychological responses and associated factors during the initial stage of the 2019 coronavirus disease (COVID-19) epidemic among the general population in China. Int $\mathrm{J}$ Environ Res Public Health. 2020; 17(5):1729.

18. Wang C, Zhao H. The Impact of COVID-19 on Anxiety in Chinese University Students. Front Psychol. 2020; 11 :1168.

19. Pantic I. Online social networking and mental health. Cyberpsychol Behav Soc Netw. 2014; 17(10) :652-657. doi:10.1089/cyber.2014.0070

20. Rajiah K, Saravanan C. The effectiveness of psychoeducation and systematic desensitization to reduce test anxiety among first-year pharmacy students. Am J Pharm Educ. 2014; 78(9).

21. Azad N, Shahid A, Abbas N, Shaheen A, Munir N. Anxiety and depression in medical students of a private medical college. J Ayub Med Coll Abbottabad. 2017; 29(1): 123-127.

22. Sümer S, Poyrazli S, Grahame K. Predictors of depression and anxiety among international students. J Couns Dev. 2008; 86(4) :429-437.

23. Fawzy M, Hamed SA. Psychological stress among medical students in Assiut University, Egypt. Psychiatry Res. 2017; 255(10.1016).

24. Chavajay $P$, Skowronek J. Aspects of acculturation stress among international students attending a university in the USA. Psychol Rep. 2008; 103(3) :827-835. 